Ophthalmologica

\title{
Intravitreal Bevacizumab to Treat Acute Central Serous Chorioretinopathy: Short-Term Effect
}

\author{
Hyun Kyung Seong ${ }^{a}$ Ji Hyun Bae ${ }^{b}$ Eung Suk Kim ${ }^{c}$ Jae Ryong Han ${ }^{b}$ \\ Woo Ho Namb Ha Kyoung Kimb \\ Departments of Ophthalmology, ${ }^{a}$ Hanil General Hospital, ${ }^{b}$ Kangnam Sacred Heart Hospital, Hallym University \\ College of Medicine, and ${ }^{\mathrm{C} C h u n g-A n g ~ U n i v e r s i t y ~ C o l l e g e ~ o f ~ M e d i c i n e, ~ S e o u l, ~ K o r e a ~}$
}

\section{Key Words}

Central serous chorioretinopathy $\cdot$ Intravitreal

bevacizumab (Avastin)

\begin{abstract}
Aims: To report the beneficial effect of intravitreal bevacizumab (Avastin) injection in patients with acute central serous chorioretinopathy. Methods: Ten eyes of 10 patients with acute central serous chorioretinopathy received an intravitreal bevacizumab (1.25 mg/0.05 ml) injection. At baseline and follow-up visits patients had best corrected visual acuity (BCVA), IOP assessment, dilated fundus examination and OCT imaging. Main outcome measures were the resolution of neurosensory detachment, improvement in visual symptoms and visual acuity. Results: All patients showed resolution of neurosensory detachment promptly, and improvement in visual acuity and symptoms within 1 month. In 1 case, fluorescein leakage resolved and neurosensory detachment nearly resolved at 2 weeks after treatment. At 6 months the mean BCVA (LogMAR) had improved from 0.32 to 0.04 , which was statistically significant ( $p=0.007$, Wilcoxon signed ranks test). No recurrence was observed during a 6-month follow-up. Conclusions: Intravitreal bevacizumab injection for acute central serous chorioretinopathy may result in prompt resolution of neurosensory detachment and reduction of angiographic leakage. These short-term results
\end{abstract}

suggest that intravitreal bevacizumab injection may constitute a promising therapeutic option in acute central serous chorioretinopathy.

Copyright $\odot 2009$ S. Karger AG, Basel

\section{Introduction}

Central serous chorioretinopathy (CSC) is one of the ten most common diseases of the posterior segment of the eye characterized by serous detachment of the neurosensory retina and frequently causes mild to moderate visual impairment. Fortunately, the disorder is self-limited in the majority of patients, who also regain excellent vision. Although the prognosis is usually favorable, some patients who do not have spontaneous resolution develop pigment epithelial and photoreceptor damage with visual impairment.

The mechanism for the development of CSC remains unclear. According to one of the hypothesized mechanisms, abnormalities in choroidal perfusion can be causative factors in CSC. Recent indocyanine green angiography in patients with CSC has demonstrated evidence of choroidal lobular ischemia and choroidal venous congestion [1-3], and also revealed multiple areas of choroidal vascular hyperpermeability in intermediate stages of the study [4-10]. The cause of the venous congestion has not 
Fig. 1. Case 1. a FA showing a focal leak at the level of the RPE. $\mathbf{b}$ OCT before treatment showing subfoveal neurosensory detachment. c One month after treatment, OCT showing resolution of retinal detachment.

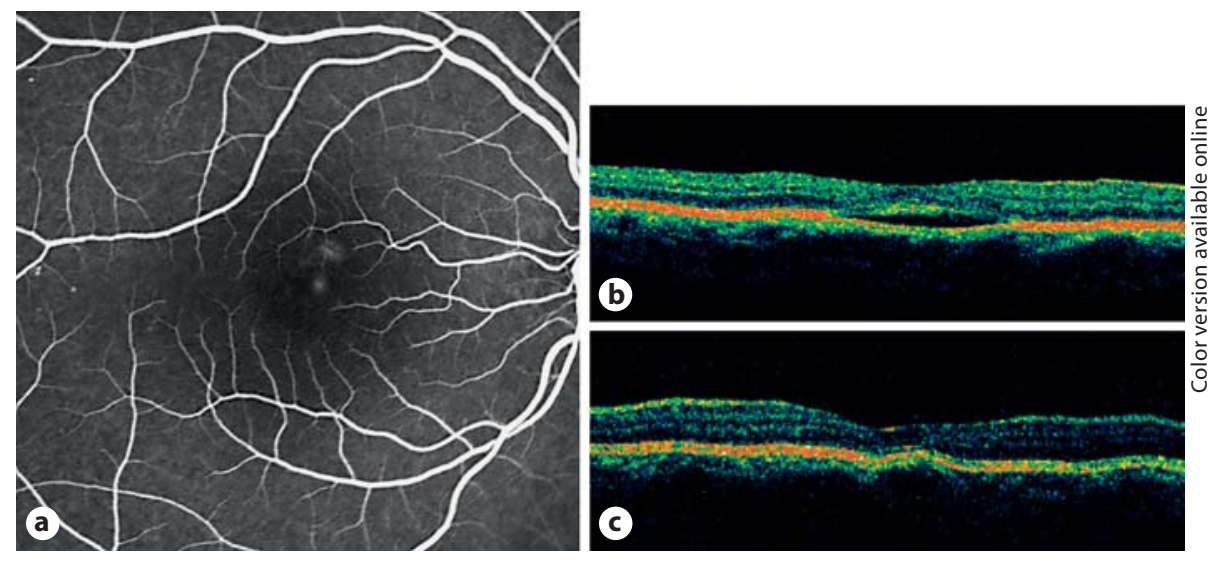

been determined, but it may be a response to ischemia and delayed arterial filling or a consequence of outflow obstruction. Choroidal hyperpermeability at foci of subretinal fluorescein leakage is a frequent finding [11-14], but choroidal hyperpermeability can also be found without associated fluorescein leakage $[15,16]$, suggesting more generalized retinal pigment epithelium (RPE) or choroidal vascular disturbance.

Vascular endothelial grow th factor (VEGF) is produced by damaged retinal and choroidal cells when abnormal vascular perfusion causes ischemia. By uncoupling endothelial cell-to-cell junctions, VEGF causes vascular permeability and edema [17]. CSC may begin with the changes in choroidal permeability. Therefore bevacizumab (Avastin ${ }^{\circledR}$, Roche, Basel, Switzerland), antibody to VEGF, may be utilized as a treatment to reduce the choroidal hyperpermeability and reverse the changes seen in CSC.

Recently there has been a case report suggesting that intravitreal application of bevacizumab, a humanized monoclonal antibody to VEGF, may have beneficial effects in chronic CSC [18]. However, we used intravitreal bevacizumab injection for treatment in a few cases of acute CSC. They showed beneficial effects including reduced leakage in fluorescein angiography (FA) and resolution of neurosensory detachment in acute CSC. The purpose of the present study is to report the use of intravitreal bevacizumab injection as a treatment for patients with acute CSC.

\section{Patients and Methods}

Patients were evaluated for the presence of acute CSC characterized by a duration of symptoms and/or retinal detachment of less than 6 months with visual disturbance. Each patient underwent best corrected visual acuity measurement (Snellen or Early
Treatment Diabetic Retinopathy Study charts), a dilated retinal examination, optical coherence tomography (OCT) and FA. Patients were treated with an intravitreal injection of $0.05 \mathrm{ml}(1.25$ $\mathrm{mg}$ ) of bevacizumab, $3.5 \mathrm{~mm}$ from the corneal limbus, using a 30 gauge needle, in the inferotemporal quadrant under aseptic conditions. All patients were informed about other therapeutic options and the off-label situation of this therapy. Treatment was performed in accordance with the ethical standards of the 1964 Declaration of Helsinki and the informed patient's consent.

\section{Selected Case Reports}

\section{Case 1}

A 50-year-old female with a history of CSC presented with complaints of blurred vision with relative central scotoma in the right eye. Visual acuity measured 25/20, and retinal evaluation revealed a central macular neurosensory detachment (fig. 1a). FA revealed a focal leak at the level of the RPE near the fovea, and OCT showed subfoveal neurosensory detachment. She had had an ocular history of CSC in her right eye 2 years ago, which had completely resolved 6 months later. Treatment with intravitreal bevacizumab injection was performed without complications. Visual acuity improved to 20/20 1 month following treatment, with resolution of symptoms and the neurosensory detachment. Retinal examination, visual acuity and OCT remained stable for 8 additional months of follow-up.

\section{Case 6}

A 36-year-old male complained of decreased vision in the left eye and inability to perform his work requiring excellent stereoscopic vision. Visual acuity measured 63/20. Retinal evaluation revealed a central macular sensory detachment and focal RPE leak was detected on FA (fig. $2 \mathrm{a}_{1}, \mathrm{a}_{2}$ ). Neurosensory detachment was also confirmed by OCT. Intravitreal bevacizumab injection was performed without complications. Two weeks after treatment, visual acuity improved to 20/20 with resolution of fluorescein leakage and nearly complete resolution of neurosensory detachment associated with marked improvement in visual acuity and work proficiency. Retinal examination, visual acuity and OCT remained stable for 6 additional months of follow-up. 

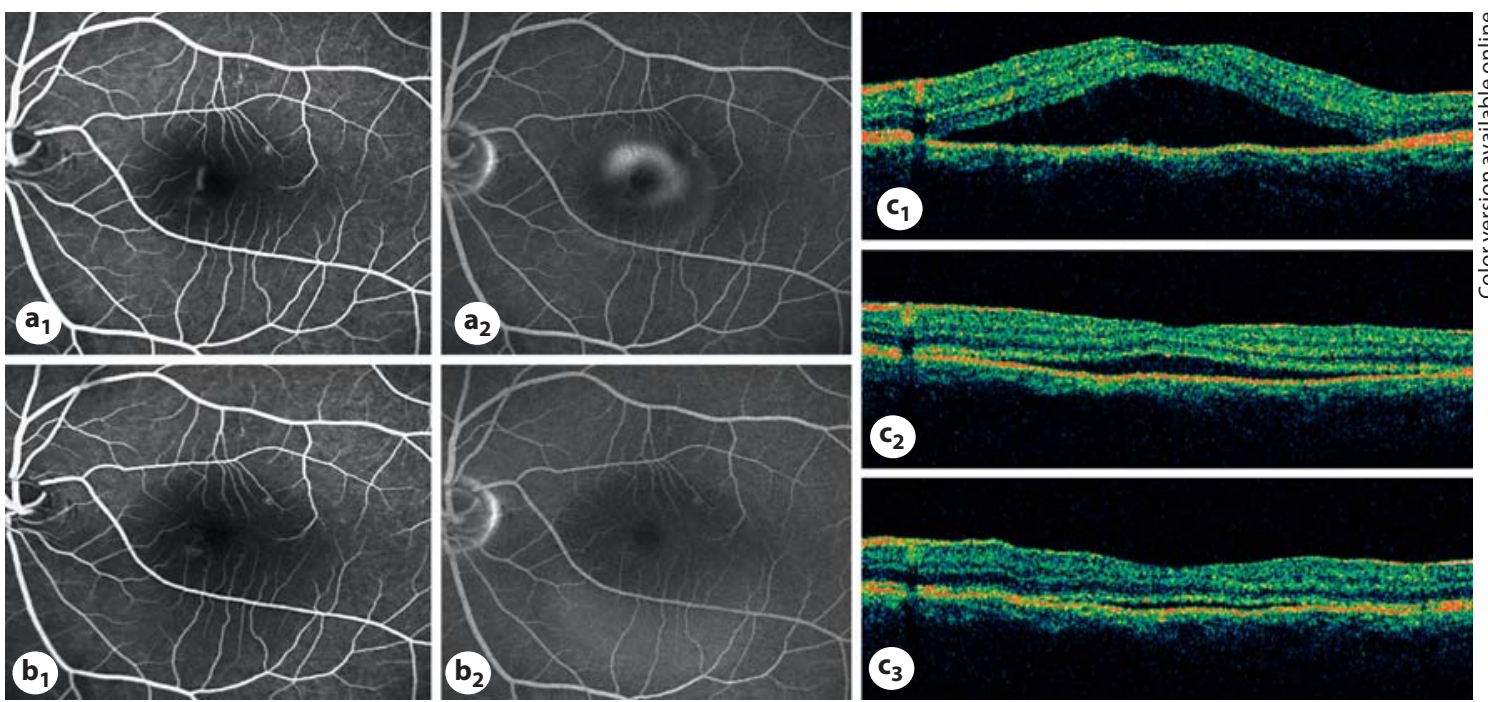

Fig. 2. Case 6. FA showing smokestack-type CSC leaking $\left(\mathbf{a}_{1}, \mathbf{a}_{2}\right)$. OCT before treatment showing subfoveal neurosensory detachment $\left(\mathbf{c}_{1}\right)$. Two weeks after treatment, FA showing mottled hyperfluorescence, consistent with a window defect without focal leakage $\left(\mathbf{b}_{1}, \mathbf{b}_{2}\right)$ and OCT showing marked resolution of subretinal detachment $\left(\mathbf{c}_{2}\right)$. Six weeks after treatment, OCT showing resolution of retinal detachment $\left(\mathbf{c}_{3}\right)$.

Fig. 3. Case 7. a FA showing a focal leak at the level of the RPE. b OCT before treatment showing subfoveal neurosensory detachment. c One month after treatment, OCT showing resolution of retinal detachment.
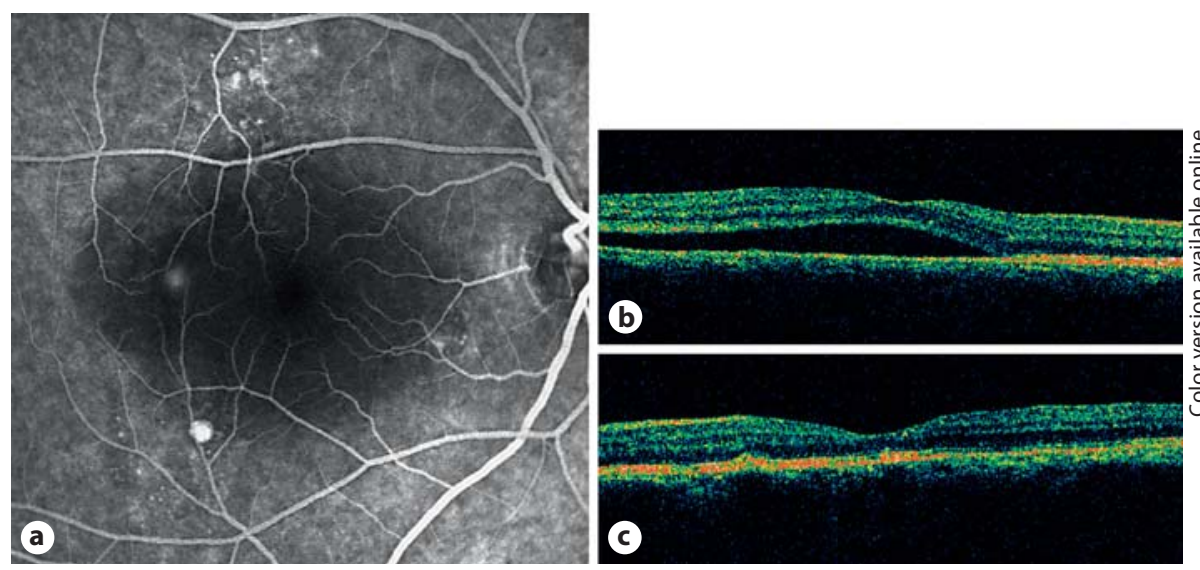

Case 7

A 42-year-old male complained of visual disturbance in the right eye for 3 weeks that interfered with his work. He had a history of CSC observed for 6 months without improvement in visual acuity and treated with photodynamic therapy (PDT) in the left eye 5 months ago. Visual acuity at the time of presentation measured 25/20 in the right eye. FA revealed two focal RPE leaks close to the center of the retina with surrounding neurosensory detachment confirmed by OCT (fig. 3a, b). The patient experienced a favorable result of PDT in his left eye. But PDT has many adverse effects, so we presented other options for treatment. After informed consent, the patient decided to try bevacizumab therapy as a new therapeutic option. Intravitreal bevacizumab injection was performed without complications. One month after treatment, visual quality improved with resolution of neurosensory detachment in retinal examination and OCT. Visual quality and visual acuity were stable at 6-month follow-up.

\section{Results}

Ten eyes of 10 patients ( 5 men, 5 women) with CSC were treated with intravitreal bevacizumab injection. Their age at the time of treatment ranged from 35 to 55 years (mean 45.2). Pretreatment visual acuity ranged from $20 / 25$ to $20 / 100$. All patients had recent exacerba- 
Table 1. Results

\begin{tabular}{|c|c|c|c|c|c|c|c|c|c|c|c|}
\hline \multirow{2}{*}{$\begin{array}{l}\text { Patient } \\
\text { No. }\end{array}$} & \multirow{2}{*}{$\begin{array}{l}\text { Age } \\
\text { years }\end{array}$} & \multirow[t]{2}{*}{ Gender } & \multirow[t]{2}{*}{ Eye } & \multirow{2}{*}{$\begin{array}{l}\text { Episode dura- } \\
\text { tion before Tx }\end{array}$} & \multirow[t]{2}{*}{ Attack } & \multicolumn{6}{|c|}{ Visual acuity } \\
\hline & & & & & & before $\mathrm{Tx}$ & 2 weeks & 1 month & 2 months & 3 months & 6 months \\
\hline 1 & 51 & $\mathrm{~F}$ & right & 2 months & 2nd & $20 / 25$ & $20 / 20$ & $20 / 20$ & $20 / 20$ & & $20 / 20$ \\
\hline 2 & 47 & M & right & 1 month & $1 \mathrm{st}$ & $20 / 63$ & & $20 / 25$ & & $20 / 20$ & $20 / 20$ \\
\hline 3 & 54 & M & left & 1 week & 3 rd-4th & $20 / 50$ & & $20 / 40$ & & $20 / 25$ & $20 / 25$ \\
\hline 4 & 43 & $\mathrm{~F}$ & left & 1 month & $1 \mathrm{st}$ & $20 / 25$ & & $20 / 25$ & $20 / 25$ & & $20 / 25$ \\
\hline 5 & 35 & M & left & 4 months & $1 \mathrm{st}$ & $20 / 32$ & $20 / 20$ & $20 / 20$ & $20 / 20$ & & $20 / 20$ \\
\hline 6 & 36 & M & left & 1 month & $1 \mathrm{st}$ & $20 / 63$ & $20 / 20$ & $20 / 20$ & $20 / 20$ & $20 / 20$ & $20 / 20$ \\
\hline 7 & 42 & M & right & 1 month & $1 \mathrm{st}$ & $20 / 25$ & $20 / 20$ & $20 / 20$ & $20 / 20$ & $20 / 20$ & $20 / 20$ \\
\hline 8 & 55 & $\mathrm{~F}$ & right & 1 week & $1 \mathrm{st}$ & $20 / 63$ & $20 / 25$ & & $20 / 20$ & & $20 / 20$ \\
\hline 9 & 44 & $\mathrm{~F}$ & right & unknown & 2nd & $20 / 100$ & $20 / 50$ & $20 / 32$ & & & $20 / 32$ \\
\hline 10 & 45 & $\mathrm{~F}$ & right & unknown & 6 th & $20 / 25$ & $20 / 20$ & & $20 / 20$ & & $20 / 20$ \\
\hline
\end{tabular}

$\mathrm{Tx}=$ Treatment.

tion of visual changes before receiving treatment and none of them had received other treatments before. All patients had one or more focal RPE leaks responsible for the neurosensory detachment, and these serous detachments of the central macula were confirmed by OCT. All patients had complete or nearly complete anatomic resolution of macular fluid and had improvement in visual acuity within 1 month after treatment. Mean pretreatment LogMAR visual acuity was 0.32 and improved to 0.04 at 6 months' follow-up, which was statistically significant ( $\mathrm{p}=0.007$, Wilcoxon signed ranks test). No patient lost vision or suffered from any significant complications related to the treatment.

\section{Discussion}

CSC is a disease of the retina characterized by serous detachment of the neurosensory retina secondary to one or more focal lesions of the RPE. The high spontaneous remission rate favors conservative management as a firstline therapeutic option. But there is some evidence supporting the benefit of early treatment for CSC. A potential benefit for early resolution may be mediated by a lower rate of RPE degeneration in the treated eye $[19,20]$, which is also warranted because of an uncertain relation between the onset of detachment and that of symptoms [21] and special occupational demands for binocular visional function.

Although there is no definite evidence about early treatment for CSC, many retinal specialists tend to consider laser photocoagulation, PDT with verteporfin and some medical treatment as early treatment $[19,22,23]$. Laser photocoagulation and PDT with verteporfin accelerate the resolution of detachment [24-30], but they should be used with caution because they can induce permanent damage to the RPE or choriocapillary, severe retinal thermal injury, subretinal choroidal neovascularization, often many years after the primary incident $[31,32]$.

One experimental study showed that PDT with verteporfin resulted in morphologic and functional breakdown of the outer blood-retinal barrier and function of RPE or RPE cells themselves with increasing concentration of verteporfin [33].

The mechanism by which intravitreal bevacizumab therapy ameliorates RPE leak and resorption of subretinal fluid in CSC is unknown. But indocyanine green angiography in patients with CSC has demonstrated evidence of choroidal lobular ischemia, choroidal venous congestion [1-3] and also multiple areas of choroidal vascular hyperpermeability, suggesting a more generalized RPE or choroidal vascular disturbance [4-10]. Choroidal ischemia in CSC may induce an increase in the concentration of VEGF. The reduction of VEGF concentration may have the desired effect in patients with CSC, with breaking the chain of events leading to neurosensory detachment.

In this small case series, we demonstrated that intravitreal bevacizumab injection in patients with CSC can bring on prompt resorption of subretinal fluid, which can be associated with rapidly improved vision. This result provided the proof principle for the current study and prompted further exploration of the treatment.

Although this case series demonstrated successful treatment of acute CSC and none of the patients experi- 
enced a significant adverse event with intravitreal bevacizumab injection, it is limited by retrospective nature, small number of patients and short follow-up. Furthermore, individuals with CSC may experience spontaneous resolution of their symptoms and leakage; our lack of a control group also does not allow one to determine if the resolution of the serous detachment and RPE leaks in our cases was actually a result of treatment or was due to the natural history of the disease. But the temporal course suggests that the improvement is likely due to the intravitreal bevacizumab injection. These results are promising, and our retrospective study may result in a prospective randomized clinical trial to evaluate if this new therapy is effective enough to be an option in the future. We also need to make further investigations into the possible role of VEGF in the pathogenesis of CSC and treatment of CSC with anti-VEGF agents to understand more precisely the risk and benefit of the therapy for patients with CSC.

\section{References}

1 Hayashi K, Hasegawa Y, Tokoro T: Indocyanine green angiography of central serous chorioretinopathy. Int Ophthalmol 1986;9: 37-41.

-2 Prünte C: Indocyanine green angiography findings in central serous chorioretinopathy. Int Ophthalmol 1995;19:77-82.

$\checkmark 3$ Prünte C, Flammer J: Choroidal capillary and venous congestion in central serous chorioretinopathy. Am J Ophthalmol 1996;121: 26-34.

-4 Stanga PE, Lim JI, Hamilton P: Indocyanine green angiography in chorioretinal diseases: indications and interpretation: an evidencebased update. Ophthalmology 2003;110:1521.

5 Piccolino FC, Borgia L: Central serous chorioretinopathy and indocyanine green angiography. Retina 1994;14:231-242.

6 Piccolino FC, Borgia L, Zinicola E, Zingirian $\mathrm{M}$ : Indocyanine green angiographic findings in central serous chorioretinopathy. Eye 1995;9:324-332.

7 Slakter JS, Yannuzzi LA, Guyer DR, Sorenson JA, Orlock DA: Indocyanine-green angiography. Curr Opin Ophthalmol 1995;6:2532.

$\checkmark 8$ Spaide RF, Hall L, Haas A, Campeas L, Yannuzzi LA, Fisher YL, Guyer DR, Slakter JS, Sorenson JA, Orlock DA: Indocyanine green videoangiography of older patients with central serous chorioretinopathy. Retina 1996; 16:203-213.

-9 Yuzawa M, Kawamura A, Yamaguchi C, Shouda M, Shimoji M, Matsui M: Indocyanine green videoangiographic findings in detachment of the retinal pigment epithelium. Ophthalmology 1995; 102:622-629.

-10 Guyer DR, Yannuzzi LA, Slakter JS, et al: Digital indocyanine green videoangiography of central serous chorioretinopathy. Arch Ophthalmol 1994;112:1057-1062.

-11 Menchini U, Virgili G, Lanzetta P, Ferrari E: Indocyanine green angiography in central serous chorioretinopathy. Int Ophthalmol 1997;21:57-69.

- 12 Uyama M, Matsunaga H, Matsubara T, Fukushima I, Takahashi K, Nishimura T: Indocyanine green angiography and pathophysiology of multifocal posterior pigment epitheliopathy. Retina 1999;19:12-21.
13 Constantinides G: Relation between retinal pigment epithelial detachment and dye leakage in central serous retinopathy. J Fr Ophtalmol 2000;23:649-654.

14 Yannuzzi LA, Slakter JS, Gross NE, Spaide RF, Costa DL, Huang SJ, Klancnik JM Jr, Aizman A: Indocyanine green angiographyguided photodynamic therapy for treatment of chronic central serous chorioretinopathy: a pilot study. Retina 2003;23:288-289.

15 Guyer DR, Yannuzzi LA, Slakter JS, Sorenson JA, Ho A, Orlock D: Digital indocyanine green videoangiography of central serous chorioretinopathy. Arch Ophthalmol 1994 112:1057-1062.

$>16$ Iida T, Hagimura N, Otani T, Ikeda F, Muraoka $\mathrm{K}$ : Choroidal vascular lesions in serous retinal detachment viewed with indocyanine green angiography. Nippon Ganka Gakkai Zasshi 1996;100:817-824.

17 Weis SM, Cheresh DA: Pathophysiological consequences of VEGF-induced vascular permeability. Nature 2005;437:497-504.

$>18$ Niegel MF, Schrage NF, Christmann S, Degenring RF: Intravitreal bevacizumab for chronic central serous chorioretinopathy (in German). Ophthalmologe 2008;105:943945.

19 Wang MS, Sander B, Larsen M: Retinal atrophy in idiopathic central serous chorioretinopathy. Am J Ophthalmol 2002;133:787793.

20 Fuhrmeister H: A long-term study of morphological and functional developments after central serous chorioretinitis. Klin Monatsbl Augenheilkd 1983;182:549-551.

-21 Wang M, Sander B, la Cour M, Larsen M: Clinical characteristics of subretinal deposits in central serous chorioretinopathy. Acta Ophthalmol Scand 2005;83:691-696.

22 Ober MD, Yannuzzi LA, Do DV, et al: Photodynamic therapy for focal retinal pigment epithelial leaks secondary to central serous chorioretinopathy. Ophthalmology 2005; 112:2088-2094
23 Pikkel J, Beiran I, Ophir A, Miler B: Acetazolamide for central serous retinopathy. Ophthalmology 2002;109:1723-1725.

24 Burumcek E, Mudun A, Karacorlu S, et al: Laser photocoagulation for persistent central serous retinopathy: results of long-term follow-up. Ophthalmology 1997;104:616-622.

25 Canakis C, Conway MD, Livir-Rallatos C, et al: Ocular photodynamic therapy in choroidal neovascularization complicating idiopathic central serous chorioretinopathy. Ophthalmic Surg Lasers Imaging 2004;35: 168-171.

26 Canakis C, Livir-Rallatos C, Panayiotis Z, et al: Ocular photodynamic therapy for serous macular detachment in the diffuse retinal pigment epitheliopathy variant of idiopathic central serous chorioretinopathy. Am J Ophthalmol 2003;136:750-752.

$\checkmark 27$ Cardillo Piccolino F, Eandi CM, Ventre L, Rigault de la Longrais RC, Grignolo FM: Photodynamic therapy for chronic central serous chorioretinopathy. Retina 2003;23:752-763.

28 Valmaggia C, Niederberger H: Photodynamic therapy in the treatment of chronic central serous chorioretinopathy. Klin Monatsbl Augenheilkd 2006;223:372-375.

29 Chan WM, Lam DS, Lai TY, et al: Treatment of choroidal neovascularization in central serous chorioretinopathy by photodynamic therapy with verteporfin. Am J Ophthalmol 2003; 136:836-845.

30 Yannuzzi LA, Slakter JS, Gross NE, et al: Indocyanine green angiography-guided photodynamic therapy for treatment of chronic central serous chorioretinopathy: a pilot study. Retina 2003;23:288-298.

31 Penha FM, Aggio FB, Bonomo PP: Severe retinal thermal injury after indocyanine green-mediated photothrombosis for central serous chorioretinopathy. Am J Ophthalmol 2007;143:887-889.

32 Kanyange ML, De Laey JJ: Long-term follow-up of central serous chorioretinopathy (CSCR). Bull Soc Belge Ophtalmol 2002;284: 39-44.

33 Mennel S, Peter S, Meyer CH, et al: Effect of photodynamic therapy on the function of the outer blood-retinal barrier in an in vitro model. Graefes Arch Clin Exp Ophthalmol 2006;244:1015-1021. 